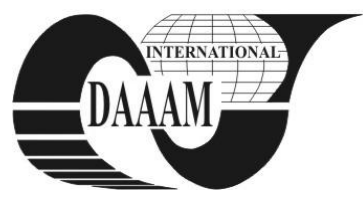

Annals of DAAAM for 2011 \& Proceedings of the 22nd International DAAAM Symposium, Volume 22, No. 1, ISSN 1726-9679 ISBN 978-3-901509-83-4, Editor B. Katalinic, Published by DAAAM International, Vienna, Austria, EU, 2011 Make Harmony between Technology and Nature, and Your Mind will Fly Free as a Bird Annals \& Proceedings of DAAAM International 2011

\title{
COORDINATE METROLOGY EDUCATION USING VIRTUAL CMM
}

\author{
BERANEK, L[ibor]; VOLF, L[udek] \& MIKES, P[etr]
}

\begin{abstract}
The article describes a concept of virtual coordinate measuring machine and its utilization for educational purposes. Our IT laboratories where substantial part of industrial metrology took a place has been equipped with software Calypso by Carl Zeiss. I would like to present my experience with this software in education.

Key words: virtual CMM, simulation, education, calypso, coordinate metrology
\end{abstract}

\section{INTRODUCTION}

In the lectures of Industrial metrology students are acquainted with measuring on coordinate measuring machines using simulation mode of Calypso software (Virtual CMM) by Carl Zeiss. Thanks to a successful cooperation between CTU and Carl Zeiss, we have 2 IT laboratories equipped with Virtual CMM workstations where students can learn basics of coordinate measuring including preparation of measurement plan. Measurement plans could be practically verified on installed Carl Zeiss C700 CMM.

\section{PREPARING THE MEASUREMENT PLAN}

Students are supposed to prepare a measurement plan (in other words "part program" or "control data") for a defined part. When measuring with Calypso, you begin by creating a measurement plan containing all the requisite tolerances and nominal data in the form of characteristics and all the requisite geometric data in the form of features. In offline programming the only suitable way of importing a data into the measurement plan is from a CAD file (Bosch, 1995). Students are guided through the process of building a measurement plan step-bystep, all the way up to the measured results. The diagram below illustrates the path we are following in lectures (Fig. 1).

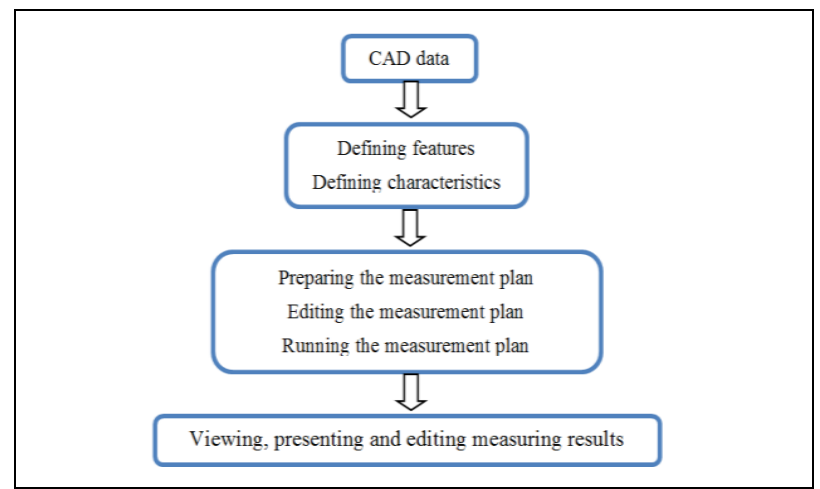

Fig. 1. The diagram of procedures from CAD model to measured results

The measurement plan is displayed in software Calypso as three lists with icons that represent the characteristics, the features and the list of prerequisites such as the names of the stylus systems, the part alignment, the clearance planes around the work piece, the coordinate systems, the temperature compensation, etc. Before the simulation of the virtual CMM can be started, several setup options on prerequisites tab need to take a place.

To allow simulation of the stylus movement, CALYPSO requires a complete geometry model of the stylus system and the associated styli. Typical stylus system prepared in the Stylus System Creator is displayed on the Fig. 2. The stylus system creator allows you to create, edit and manage the stylus system models in the form of SSC files (Christoph et al., 2008). These files are then imported into CALYPSO to simulate the used styli.

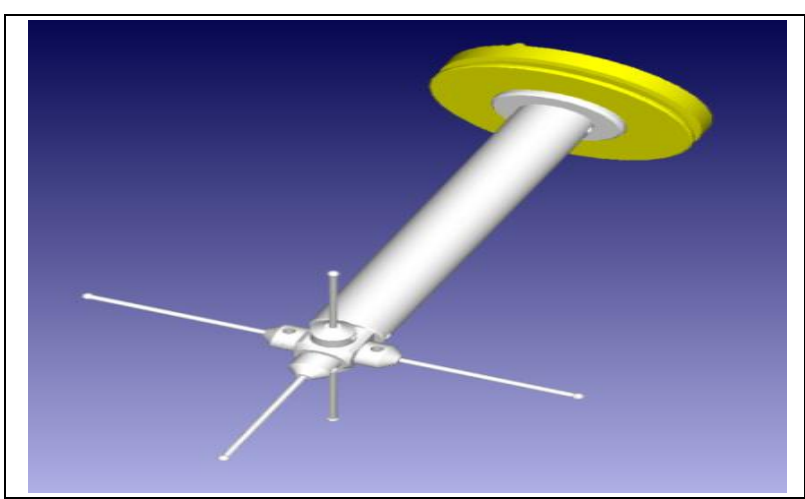

Fig. 2. An example of stylus system model used on Virtual $\mathrm{CMM}$

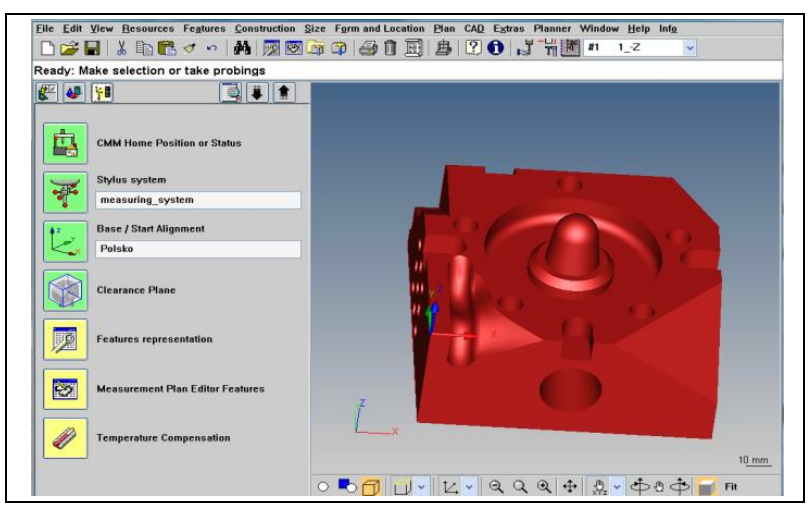

Fig. 3. Basic screen of Calypso software with CAD model, and complete list of prerequisites

Basic screen of Calypso software is shown of Fig. 3. Next to $\mathrm{CAD}$ window there is a display of the list of prerequisites. This list contains all the settings you have to configure before you create a measurement plan or run a work piece measurement. According to Fig. 3 and the list of prerequisites from top to the bottom the Virtual CMM has been properly initialized and referenced, stylus system is qualified, and the part alignment is defined as well as clearance zone around the work piece for CMM movements (Pfeifer T. et al., 2006). 
Together with the prerequisites, the features and the characteristics form the framework of the measurement plan. A feature is an element that is to be measured by the CMM. Features contain the nominal geometry, which is used for the purpose of evaluating the size, shape and position. The features are assigned to the associated characteristics. Software could automatically recognize the geometric elements and generate probing paths, strategies, retract movements and travel paths between the elements. All these features can be widely modified. The characteristics enable operator to check the tolerance limits that the work piece should meet. You have to integrate the characteristics in the measurement plan and link them with the measured features. If those features are already defined, will be defined or are supposed to be imported from a CAD file later, it makes no difference (Placko, D., 2006, Ratajczyk, E., 2005).

\section{SIMULATION}

Once all prerequisites, features and characteristics are properly chosen the simulation of measurement could be initiated (Smith, T.G., 2002). When you activate the stylus system simulation, not only the work piece but also, the CMM and the movement of the currently used stylus system is shown in the $\mathrm{CAD}$ window during the $\mathrm{CNC}$ run where you can trace the stylus system, detect collisions, and you can see exactly which stylus is used.

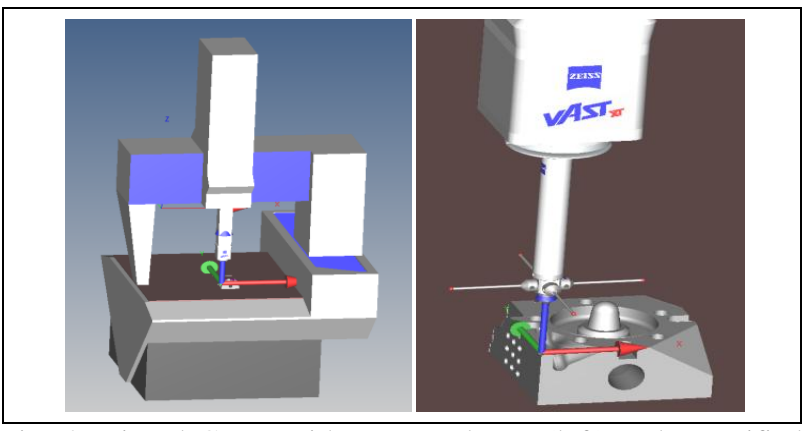

Fig. 4. Virtual CMM with measured part (left) and magnified stylus system simulation

Every time a measurement is performed, results could be presented in different printouts. The printouts are logs that are generated while the measurement plan is running. CALYPSO offers three different printouts. The Default Printout is a log of all results obtained in measurement which cannot be configured. The Compact printout is shorter than the default printout. It lists the characteristics together with the measured features for quick assessment. The most flexible is a Custom printout which can be easily configured (Fig. 5). Variability of measured results on CAD model which represents nominal values is caused by internal generator of random measured values with specified range.

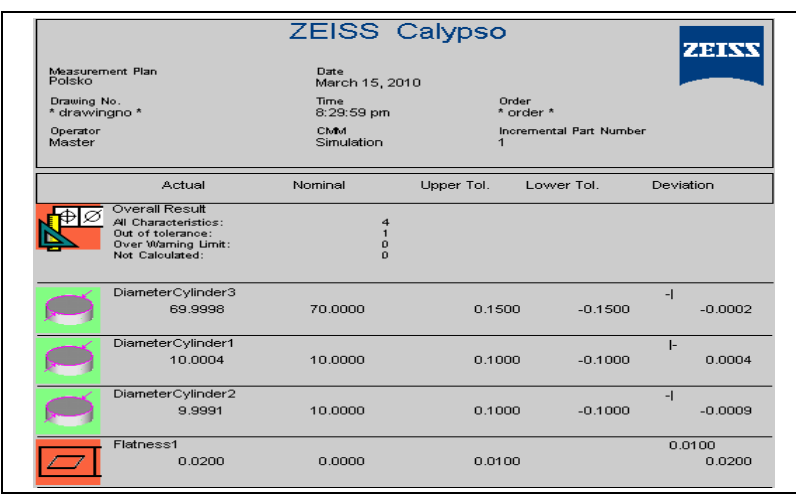

Fig. 5. An example part of the Custom printout for a measured part and selected characteristics
The results of the characteristics are color-coded: green means within tolerance, red means out of tolerance. Measured values are in the first column labeled Actual then we can confront results against nominal values and upper and lower tolerances. Because our Virtual CMM is equipped with Vast $\mathrm{XT}$ probe that allows active scanning, we can collect great amount of points in short time.

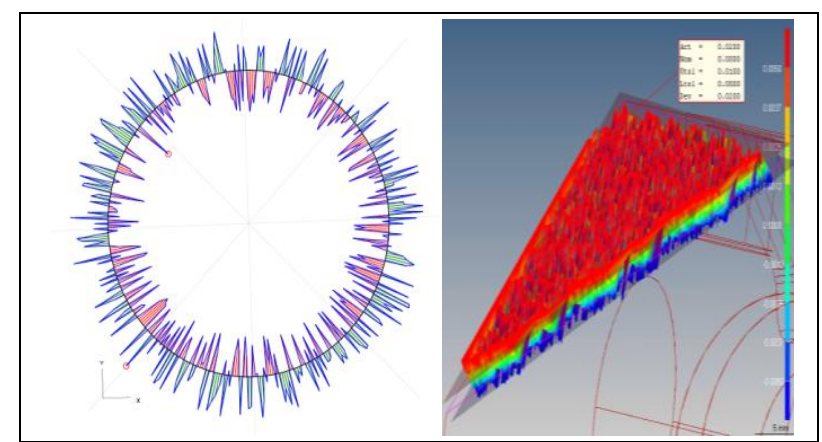

Fig. 6. An example of graphics analysis of roundness of selected hole and flatness of selected plane

On the Figure 6 is analysis of flatness of selected plane visualized on CAD model, with both tolerances and numeric results in dialog window, plain has been scanned using Grid strategy with step width $0,05 \mathrm{~mm}$ (9245 points measured).

Concept of Virtual CMM greatly enhances possibilities of education of coordinate measuring in classes of Industrial metrology because all students are working actively contrary to education on real CMM, where it is impossible to involve all students into the practical preparation of part program.

\section{CONCLUSION}

Knowledge of industrial metrology was always an important part of mechanical engineer education at Czech Technical University in Prague. In the last two years much progress has been done. Efficient introduction of coordinate metrology into the education was possible only thanks to the completion of real CMM by its virtual form. Now each student of a class is capable to acquire the basic procedures for coordinate measurement practically. The next step in the innovation of education is to transfer knowledge gained in the Metrology Centre Carl Zeiss, which is a joint venture of company Carl Zeiss and the Faculty of Mechanical Engineering CTU in Prague.

\section{REFERENCES}

Bosh, J. A. Coordinate Measuring Machines and Systems. Marcel Dekker, ISBN 0-8247-9581-4, New York, 1995

Christoph, R., Neuman, H. J. Multisensor Coordinate Measuring Machines. L. V. Print, Uherské Hradiště: 2008. $106 \mathrm{p}$.

Pfeifer T., Imkamp D., Schmitt R.; Coordinate Metrology and CAx-Application in Industrial Production. Hanser, Munich 2006

Placko, D. Metrology in Industry: The Key for Quality, French College of Metrology, ISBN 978-1-905209-51-4, London, 2006

Ratajczyk, E. Wspolrzednosciowa technika pomiarowa. Coordinate measuring technique. Warszawa: Oficyna Wydawnica Politechniki Warszawskiej, 2005. 356 s.

Smith, T.G. Industrial Metrology, Surfaces and Roundness. Springer, ISBN 1-85233-507-6, London, 2002 